\title{
Exploring Pragmatic Failure into the Writing of Young EFL Learners: A Critical Analysis
}

\author{
Peter Yunlin Muir \\ National Basic Foreign Language Teaching and Research Center, Beijing 100044, China \\ E-mail: pjsmuir2006@gmail.com \\ Zongfang $\mathrm{Xu}$ \\ Zhongming High School, Tongling 244100, China \\ E-mail: juliahsui@yahoo.com.cn
}

Received: May 30, 2011

Accepted: June 27, 2011

Published: December 1, 2011

doi:10.5539/elt.v4n4p254

URL: http://dx.doi.org/10.5539/elt.v4n4p254

\begin{abstract}
This present study provides overviews of the phenomenon in EFL writing instruction in basic education in mainland China, which in its natural sense never proceeds among young learners at high school level. Then it investigated 34 students' short in-class compositions. Beyond many spelling and syntactic errors, their pragmatic failures are therefore categorized into pragmalinguistic and sociopragmatic failures in accordance with Jenny Thomas (1983). It finds that pragmalinguistic failures are as follows: verbose appositions, combination of two subordinate clauses, misunderstandings of word meaning, Chinese construction of sentences, run-on sentences, independent subordinate clauses, the omission of relative pronouns and that sociopragmatic failure, considerably rare, lies in their perception and expression of specific Chinese-based pragmatic conventions. The author argues that the causes of pragmatic failure are their limited language proficiency and L1 pragmatic transfer.

Based on the investigation and findings of the study, the author puts forward some tentative solutions to achieve pragmatic appropriateness in writing: (1) Appropriate in-class introduction of target language pragmatic knowledge and culture; (2) The awareness of distinguishing the target language with L1.
\end{abstract}

Keywords: Pragmatic failure, Pragmatic transfer, Appropriateness, Written production, Young EFL learners

\section{Introduction}

Even though EFL learners can understand the utterances by native speakers (NSs) after some years of learning, they seem to produce what is more likely to resemble their mother language than the target language. As is the case in almost all my classroom observations, when they read the adaptations required in EFL classrooms with multiple choice questions (MCQs), they can (though not fully most of the time) apprehend the conveyance of meaning through syntax and a basic vocabulary composed of words and conventionalized expressions. However, the gap between input and output of language never dies out as one wishes; they fail to assimilate what they apprehend, then incline toward their mother culture norms. What they produce will be actually apprehended only when it is translated into Chinese word-to-word by their mother language interlocutors. What kinds of errors/failures exist in their language production? Selinker (1972) has listed five factors which directly affect the output of learners' interlanguage system:

1. Language transfer - fossilizable items, rules, subsystems which occur in the interlanguage as a result of transfer from the native language.

2. Transfer of training - items resulting from particular approaches used in training.

3. Strategies of second language learning - identifiable approaches by the learner to the material being learned.

4. Strategies of second-language communication - identifiable approaches by the learner to communication with native speakers of the target language.

5. Overgeneralization of target language linguistic material - overgeneralization of target language rules and semantic features.

By viewing the shape of utterances originating in learners' interlanguage, as affected by the above categories, we 
can better see, according to Selinker, the nature of the psychology of second language learning.

While the errors/failures at linguistic level are easily investigated, those in the angle of pragmatics are even more difficult to find and instruct. Such failures are caused mainly because of learners' mother culture tokens, namely different connotations and denotations (or even referents) of words, way of thinking, etc..

Thus the purpose of this study is to investigate the situation of EFL written production among young learners at high school level, to analyze the pragmatic failure existing in their production and to attain some insights into teaching methods in basic EFL writing.

\section{Defining Pragmatic Failure}

\subsection{Definition}

Throughout the literature of interlanguage pragmatics, we frequently find examples of communicative breakdowns or deviations in the target language on the part of learners of that language. Eisenstein and Bodman (1993), for instance, in looking into nonnative speakers' (NNSs') expressing gratitude in American English note that though the NNSs are successful on the whole in responding in a native-like manner to situations requiring simple, phatic, ritualized expressions of gratitude, they are not able to approximate acceptable native speech act in a significant number of cases (items requiring complex speech act sets). "In fact, their difficulties in adequately expressing gratitude in native-like manner were extensive and severe." (Eisenstein \& Bodman, ibid: 68) The language learners are found to make mistakes/errors at discourse level as well as at syntactic level. For instance, in expressing gratitude for dinner, they will say "Thank you very much for dinner. You will come to our house next week?", at which the native may feel that they were obligated. They may also lack the words and syntax to work their way through culturally familiar and unfamiliar situations.

Such is the example of deviations from a target language in the comprehension and production on the part of the NNSs of that language, which may result in breakdowns or discomfort in cross-cultural communication, are referred to as instances of "pragmatic failure". Thus pragmatic failure can be defined as "the inability to use language effectively and to understand what is meant by what is said" (Thomas, 1983).

\subsection{Categorizing pragmatic failure}

Jenny Thomas (1983) has distinguished two kinds of pragmatic failure: pragmalinguistic failure and sociopragmatic failure. She referred to pragmalinguistics as the study of the relation between pragmatics and different branches in linguistics, especially the relation between pragmatics and grammatical forms. She argued that "the pragmatic force associated with a given linguistic structure in one language may be different from the force associated with the corresponding linguistic structure in another." Accordingly, cross-cultural pragmalinguistic failure occurs when the pragmatic force mapped by the NNS onto a given linguistic structure is systematically different from that normally assigned to it by a NS of the language, or when speech act strategies are inappropriately transferred from L1 to L2. Sociopragmatics, according to Thomas, studies social and cultural components in language use, especially the use of language appropriate to different social context, and pragmatic failures committed by NNSs due to the fact that the cultural differences are referred to as sociopragmatic failures.

Undoubtedly, Thomas's distinction of these two kinds of pragmatic failure from the point of view of the gradience from grammar to sociology is of operational significance in accounting for NNSs' difficulties in interacting with NSs. The terms have been widely accepted and adopted by later researchers in studying cross-cultural miscommunication. So we have altogether four categories of pragmatic failure:

(1) Interpretative pragmalinguistic failure occurs when the NNS fails to infer the contextually appropriate meaning of a linguistic form in the target language, or misinfers the illocutionary force of the utterance in the target language. An example is about what Americans would regard as a compliment: "You look sexy." When an American young lady hears this, she would gladly accept it and express appreciation of the compliment. However, a Chinese young lady will wrongly take it as impolite and even villainous, for she does not know the pragmatic force of the word "sexy" which in English implies beauty of women.

(2) Interpretative sociopragmatic failures are due to socio-cultural differences between L1 and L2. So if the NNS assesses the social parameters such as power, distance, rights and obligations against those in his/her own culture while processing an utterance in the target language, sociopragmatic failures are likely to occur. Take, for instance, the invitations by the American people. The NNSs of English often report that they have difficulties in apprehending the Americans and sometimes they complain about the Americans' insincerity, for when the Americans give invitations such as "We really must get together sometime" or "Let's have lunch together soon", they sometimes do not mean that. In that case, invitations function more as an indication of inter-personal relations than as a real social commitment. 
(3) Productive pragmalinguistic failures are caused when the NNS maps into a linguistic form an inappropriate force in producing an utterance, that is, they mainly stem from the mismatch between a certain linguistic form and a certain illocutionary force. It is most typically shown in the phrase "of course", for example,

\section{A: Is it open on Sunday?}

B: Of course.

In general, "of course" means "yes, indeed", but it does not always equal that. In the above example, A is likely to infer from B's "of course" a meaning like "Only an idiot foreigner would ask!" and thus feel offended.

(4) Productive sociopragmatic failures, like interpretative sociopragmatic failures, arise from the differences of social parameters between different cultures, but related to the NNS's ability of performing linguistic actions. For instance, Chinese students are often found to respond to compliments by saying "I'm flattered (ashamed)." or "No, no, not at all." or other self-deprecating forms, where an appreciation of the compliment is more appropriate, for instance, "Thank you. It's very kind of you to say so." It should be remembered that the distinctions between the categories are not clear-cut and a failure at the process of interpretation may easily lead to a failure in production, which also gives rise to cross-cultural difficulties.

\section{The Phenomenon of Pragmatic Failure in Secondary EFL Writing}

\subsection{Subjects}

Due to the objectives of this investigation, junior high school EFL learners are chosen for this study. Moreover, in order to explore more detailed observation, the subjects are now further restricted into the ninth graders. Mostly they have learnt English for four years in primary school and over two years in junior high school. 34 short essays are then collected during a composition quiz with several different writing prompts in Chinese. The topics include "an English teacher", "using mobile phones", "after-class life", "health", "study", "environment", "ads", etc. They composed those short essays in one period of class time (45mins). They are free to turn to dictionaries when necessary.

\subsection{The phenomenon of pragmatic failure in writing}

Their pragmatic failure lies in the following:

(1) Pragmalinguistic failure

Pragmalinguistic failures are found as follows:

a. Verbose appositions

[1] Mr. Cheng, my English teacher, he is a kind man.

b. Combination of two subordinate clauses

[2] Because of that, so I must study hard to enter key senior middle school.

[3] He has taught students for about eight years. Although so long, but he still loves his job.

[4] Because I have to spend three or four hours in finishing homework, so I can't go to sleep until midnight.

[5] Since the time to speak English in class is so limited, so we should try hard to do more practice after class.

c. Misunderstandings of words

[6] The best reason is our $P E$ is developing all the time.

[7] "Healthy life style is good medicine." This sentence is right and very useful.

[8] I will go to attend the English Summer Camp in July next year. I want to live at your home.

I'm very happy to live in your home.

[9] I have lost a lot of lessons.

d. Chinese construction of sentences

[10] Now there are many students take mobile phones in the middle school.

[11] My result was go down along straight line.

[12] I'm a like English's girl.

[13] I have a good something to you say.

e. Run-on sentences 
[14] Everyone makes a contribution, the world will become much more beautiful.

[15] There are lots of products, ads can help us choose one for our needs.

f. Independent subordinate clauses

[16] My hobby is reading and listening to music. Do you know why I like reading? Because books are our good friends. They can give me knowledge and make me happy.

It says we should protect our environment. Because it is our duty to protect it.

g. The omission of relative pronouns

[17] The most problem is our environment is harmed.

[18] There are many exercises are waiting to be finished for us.

(2) Sociopragmatic failure

Sociopragmatic failure seems to be considerably rare.

[19] They're too young to playing interesting games on the phone.

They think the students are too young to use the phone.

But teachers think that we shouldn't have a mobile phone. Because we are young. (here exists an independent subordinate clause)

[20] I'm very appreciate him. (incorrect) (see discussions in Eisenstein \& Bodman, 1986) I say "thank you very much" to him, but he said, "It is my duty."

[21] I and Zhang Fang also plant some trees.

[22] I have been awarded three good students many times.

[23] A good ad can bring art feelings.

\subsection{Analysis of pragmatic failure}

As listed in the above section, the nature of pragmatic failure has been unfolded. Learners of junior high school tend to produce pragmatic failure in the two categories in accordance with Jenny Thomas (1983).

Pragmalinguistic failures are found especially normal. They misuse appositions as a source of spoken communication. In [1], he is verbose, which is often the case when a speaker utters. In spoken communication, among English and/or Chinese interlocutors in my investigation, they employ a pronoun (e.g. he here) to refer to the mentioned person, expressing a kind of small pause.

The second is combination of two subordinate clauses. Cases are found when they express the relation of cause-effect, and the adverbial of concession. This has already been confirmed in many previous studies (e.g. Cai, 2006), which is perhaps even more severe among learners of junior high school. Chinese is so strong in expressing the above two relations that it requires the coexistence of "because" and "so", "although" and "but". Therefore, it is rather natural that the subjects perform utterances like [2], [3], [4], [5]. It is explicitly the result of their L1 pragmatic transfer.

Thirdly, misunderstandings of words are the seeds planted when they are acquired in the vocabulary class. In [6], actually the subject wants to say "athletics", while he employs the term $P E$, short for physical education, referring to merely a school course. [7] can be revised as "The saying/statement is true and it helps a lot". In the two utterances in [8] "live" is mistaken for "stay". If a stranger will "live" with a NS family, the host is sure to feel offended unless the stranger is a language exchange student. [9] can be revised as "I have missed a lot of lessons".

Fourthly, Chinese construction of sentences cannot usually get across to NSs. In my experience, even any mature learners of English (e.g. their teachers of English) will feel embarrassed when reading their essays. The utterances in this category can be revised as follows:

[10b] Now there are many students taking mobile phones to school.

[10c] Many students are taking mobile phones to school.

[11b] My result was dropping sharply.

[11c] I dropped behind soon after.

[12b] I'm a girl who likes English.

[13b] I have something good to say to you. 
Fifthly, run-on sentences are a basic way of construction among young EFL learners. It is the general phenomenon in Chinese (Cai, 2006), while in English conjunctions are normally employed for such circumstances, or it is appropriate to separate it into two simple sentences or to connect the two parts with a semicolon if the meaning is not conveyed thoroughly. Thus the utterances in this category can be revised as follows:

[14b] If everyone makes a contribution, the world will become much more beautiful.

[15b] There are lots of products; ads help us choose one for our needs.

[15c] There are lots of products. Ads help us choose one for our needs.

Sixthly, independent subordinate clauses never occur except for orally short responses (for instance, responses to why-questions in the above mentioned examples).

[16b] ... Do you know why I like reading? It's because books are our good friends. ...

It says we should protect our environment, because it is our duty to protect it. (not a perfect reason here)

Lastly, the omission of relative pronouns also has its source of L1 negative transfer. The two examples in this category can be revised as follows:

$[17 \mathrm{~b}]$ The most [...] problem is that our environment is harmed.

[18b] There are many exercises which remain to be finished.

Thinking of the composition in Chinese at high school level, the language is considerably monotonous. Culture-denoted idioms are therefore seldom seen in such texts. On the analogy of this, sociopragmatic failure seems to be considerably rare among these junior high school subjects.

In the three example sentences in [19], NSs will feel confused and query why young students can not have a mobile phone. It is the result of a typical Chinese tone of reproach. [20] reflects the characteristic of spoken communication, in which "it is my duty" used as a response to "thank you very much" belongs to Chinese-based pragmatics, as is argued by Honna (2006:117). The first person goes first in Chinese pragmatic norms, while in English it always goes last, like "Zhang Fang and I" for [21]. In [22] the term "three good students" is totally a Chinglish fabrication, which is never interpreted unless paraphrase is attached. Such terms appear normally in the mainland China's media such as China Daily, Shanghai Daily, or the Beijing Today weekly (Honna, ibid.:116). [23] reflects the angle of Chinese-based pragmatics, also. To be native-like, it can be revised as "A good ad is an artistic treat".

\subsection{Causes of pragmatic failure}

As discussed above, pragmatic failure is caused by sociocultural differences as well as lack of linguistic proficiency. Even if two cultures are shown to be compatible in terms of perception of social situations, and are even shown to manifest similar levels of directness, we might still misunderstand the observed similarity in behavior if we do not take into account the dimension of cross-cultural variation, for "cultures may vary in the social meaning attached to similar linguistic choices" (Blum-Kulka \& House, 1989:136). So if a NNS cannot produce or understand the language as a NS does, inappropriately employing one expression when another is preferred, or transferring certain speech act strategy from L1 to L2, he/she may find himself misunderstood or even awkward when communicating with a NS in the target language. So it is obvious that pragmatic transfer can be counted as the main cause of various pragmatic failures in the writing of young EFL learners.

\subsubsection{Pragmatic transfer}

It has already been noted that pragmatic transfer, or first language interference affects NNSs' interlanguage proficiency, and some researchers (Wolfson, 1989) even carried out studies to find evidence for pragmatic transfer. Transfer has been found to exist and cultural norms regarding proper behavior are found to have a direct bearing on the extent to which a particular group shows a tendency to transfer rules from their mother language.

The above studies adequately testified that pragmatic transfer indeed exist, exerting some negative influences on L2 learners' pragmatic performance in the target language.

\subsubsection{Linguistic proficiency}

Pragmatic failure is not just caused by pragmatic transfer, as Wolfson said when investigating apologies: In contrast to more recent findings, NNSs were found to deviate from NS norms not only as a result of transfer but also because their L2 proficiency was inadequate to express the appropriate degree of regret (Wolfson, 1989:143).

The significant phenomenon we present that the learners tend to fail in performing a native-like language production can also be considered to be a result of low linguistic proficiency. Obviously linguistic proficiency plays an unignorable role in affecting language learners' language competence and their written and oral communication with 
native readers/hearers.

\section{Tentative Solutions}

Based on the investigation and analysis throughout the ninth graders' written production, we have found the fact that pragmatic failures exist universally in their writing. As a means of language communication, writing is not just the construction of words, paragraphs, and texts; it is a channel of communication restricted by various cultural factors. In order to avoid failures as such, we (not only students but teachers) should be sensitive of the sociocultural norms and their variations in Chinese as well as English. Thus on a psychological basis, we improve our pragmatic competence, especially cultural awareness through each language encounter. What we frequently consider is that culture awareness emerges through culture knowledge we learn explicitly as especially a course or a seminar. Therefore, fusion model of culture into language instruction is a good choice when we deal with culture ingredients. Meanwhile, as one of the five suggested ingredients of language curriculum objectives in language syllabus, cultural awareness, illustrated in a wheel, contains cultural knowledge, cultural understanding, cross-cultural communication, cultural perception and insights (Ministry of Education, 2001:6; Ieong, 2003). Culture instruction goes at two levels, i.e., cultural knowledge and cultural understanding, and the ligament in between (cross-cultural awareness) (Cao, 1998). It is believed that foreign language teaching goes in the process from cultural knowledge to cultural understanding. Communication can be realized only if the interlocutors get across the cultural conventions, beliefs, values, etc. to each other. Therefore, writing as a means of written communication is required to be reformed in its methods.

\subsection{Appropriate in-class introduction of target language pragmatic knowledge and culture}

Traditional language teacher education does not include sufficient pragmatics, as has had negative influence on the awareness of pragmatics among high school EFL teachers. Furthermore, more seriously because of the present national evaluation system, TEFL practice in mainland China's high schools merely focuses its attention on language skills, i.e., listening, speaking, reading and writing at the linguistic level. "It takes the process of foreign language learning simply as the process of receiving and transmitting language knowledge." (Muir, 2007:38) According to my investigation, it is the common phenomenon that classroom teachers (mainly non-NESTs) in high schools are fond of language usage rather than use. Writing instruction is merely practice during various testing cases. There is not any regular writing instruction in the phase of foundation. Thus learners' incomplete extension or use of target language pragmatic norms cannot be corrected at proper time, while learners themselves may take it for granted that they completely get across.

Culture is always embedded in a language. Classroom SLA needs to include (contains naturally, but we have to employ the term include to emphasize our neglect as yet) the target pragmatic norms and the development of related awareness. For instance, in vocabulary teaching, tendencies should go beyond the Chinese equivalent, or a bit luckier, the lexicographic meaning. Pragmatic meaning and lexicographic meaning are related to each other at the deep level while contrasting with each other at the superficial level (Yang \& Liu, 2005). The differences and relevance between them indicate that pragmatic meaning can and can only be incorporated into lexicographic meaning to a high degree as this has important implications for appropriate use of a word. This is particularly true when understanding an idiom.

\subsection{The awareness of distinguishing the target language with L1}

Language awareness permeates through the whole learning process of the target language. Students should be sensitive to the target language norms at the start of learning. In every phase of TEFL in high school, teachers are thus obliged to develop learners' (and their own as well) awareness in language perception. For instance, in the vocabulary teaching, do not just concentrate on the form and its lexicographic meaning (or even Chinese equivalent), but rather on its pragmatic meaning. This is also particularly true in the teaching of reading skills, for texts at any level have an abundant supply of the target culture. Therefore, teachers must make full use of the teaching materials in hand to help the students obtain the background information and improve their pragmatic competence. Once coming across specific target language pragmatic features, we must see to it that explicit instruction is required to facilitate immediate internalization. And I argue that "reading-to-writing" approach is one of the effective ones to avoid Chinese-based pragmatics and to improve learners in the pragmatic appropriateness while writing.

\section{Conclusion}

In second language learning, language competence is not equal to pragmatic competence. Language competence is the base and explicit to be taught; pragmatic competence, however, is somewhat beyond it. Without this basic understanding, no pragmatic competence can be acquired. Therefore, the phenomenon of pragmatic failure through EFL writing has to be instructed in writing class. Non-NESTs should ensure that their teaching is based on the target 
culture notions, whether they are teaching a single word or a complex text. Only with enhancing pragmatic knowledge and awareness could we help the students improve their pragmatic competence and eventually achieve pragmatic appropriateness in their EFL written production.

\section{Acknowledgements}

I deeply appreciate the feedback I received on the American speech acts of appreciation of compliments, invitation, etc. from Donald Bennett, a native American teacher whom I worked with during the academic year 2009/2010. I would like to express my gratitude to the anonymous referees of this paper for their insightful comments and favorable evaluation.

\section{References}

Blum Kulka, S., \& J. House. (1989). Cross-cultural and situational variation in requestive behavior. In S. Blum Kulka, J. House, \& G. Kasper (Eds.), Cross-cultural Pragmatics: Requests and Apologies. Norwood, NJ: Ablex. pp 123-154.

Cai, J. G. (2006). A Contrastive Study of Writing \& Rhetoric in English \& Chinese ( $2^{\text {nd }}$ ed). Shanghai: Fudan University Press. (Chinese)

Cao, W. (1998). Two levels in English culture teaching. Foreign Language Teaching \& Research, 3, 10-14. (Chinese)

Eisenstein, M., \& J. W. Bodman. (1986). 'I very appreciate': Expressions of gratitude by native and non-native speakers of American English. Applied Linguistics, 7(2), 167-185. http://dx.doi.org/doi:10.1093/applin/7.2.167

Eisenstein, M., \& J. W. Bodman. (1993). Expressing gratitude in American English. In Kasper, \& Blum-Kulka (Eds.), Interlanguage Pragmatics. Oxford: Oxford University Press. pp 64-81

Honna, N. (2006). East Asian Englishes. In Kachru, Kachru, \& Nelson (Eds.), The Handbook of World Englishes. MA: Blackwell Publishing Ltd. pp 114-129. http://dx.doi.org/10.1002/9780470757598.ch7

Ieong, S. S. L. (2003, December 9-11). Curriculum content and materials development: A 'two-wheel' strategy. Paper presented at the seventh conference on the English "Four-in-One" Teaching Approach, Zhenzhou, China.

Inbar, O. (2005). Young EFL learners [PowerPoint Slides]. [Online] Available: http://www.ph-ludwigsburg.de/html/9e-aaax-s-01/seiten/SymposiumBB/ofra_inbar.ppt

Inbar Lourie, O. (2010). English only? The linguistic choices of teachers of young EFL learners. International Journal of Bilingualism, 14(3), 351-367. http://dx.doi.org/10.1177/1367006910367849

Inbar Lourie, O., \& E. Shohamy. (2009). Assessing young language learners: What is the construct? In M. Nikolov (Ed), The Age Factor and Early Language Learning. Berlin, Mouton de Gruyter. pp. 83-96

$\mathrm{Mu}$, L. (1994). Pragmatics issues in English language teaching. Social Science Journal of Hainan University, 1, 105-108. (Chinese)

Muir, P. (2007). Toward culture: Some basic elements of culture-based instruction in China's high schools. Sino-US English Teaching, 4(4), 38-43

P. R. China. Ministry of Education. (2001). Full-time Compulsory Education and Senior High School English Curriculum Standards (Trial). Beijing: Beijing Normal University Press. (Chinese)

Selinker, L. (1972). Interlanguage. International Review of Applied Linguistics, 10, 209-231. http://dx.doi.org/10.1515/iral.1972.10.1-4.209

Thomas, J. (1983). Cross-cultural pragmatic failure. Applied Linguistics, 4(2), 91-112. http://dx.doi.org/10.1093/applin/4.2.91

Wolfson, N. (1989). Perspectives: Sociolinguistics and TESOL. Cambridge, MA: Newbury House.

Yang, W. X., \& S. M. Liu. (2005). Pragmatic meaning and lexicographical meaning: Differences and relevance. Journal of PLA University of Foreign Languages, 28(1), 20-23. (Chinese)

\section{Notes}

Note 1. Young EFL Learners: Many of the scholars (e.g. Inbar, 2005; Inbar-Lourie, 2010; Inbar-Lourie \& Shohamy, 2009) in TEFL research employ the term "young EFL learners" when it comes to the starting age of EFL learning. As a matter of fact, it may not be necessary to make it specifically technical and age-relevant; compared to "adult learners", the term "young EFL learners" in this study is referred to as EFL learners at both primary and secondary level. 
Note 2. MCQs: It is the dogmatism in ELT in mainland China, where learners are instructed to complete test-oriented MCQs although MCQs do not always display the main idea adequately but hurt the entire reading of an essay. It has already had some negative consequences-sometimes resulting in aggravating the passive psychology of reading and therefore hindering learners' development of target language writing skills. 